\title{
A Scientific Backdrop to Climate Change Policy ${ }^{1}$
}

\author{
Sean Weaver
}

\section{Introduction}

Never before in history have we known so much about the earth and our interactions with it. Science has been a great investment, and now scientists the world over are sending a solemn warning: we are changing the climate, and the threat this poses to the economy and society is significant. These threats are not merely a marginal concern. They relate to the natural resource backbone of economic and political life.

This paper offers an introduction to basic climate change science for policy makers. Presenting this backdrop helps to set a context for policy development by exploring the bigger-picture issues that policy makers will need to address in coming decades. In the process, it signals how climate change has an impact on a wide range of policy frameworks, necessitating an integrated policy response.

This scientific story is built on what is now a broad consensus in the climate science community. This consensus is based on an understanding that:

- climate change in general is a natural feature of the global climate system and always has been;

- climate change is a function of the dynamic interrelationship between many components of the climate system (including greenhouse gas concentrations); and that

- if humans change any combination of those components, we have the ability to influence the climate system.

The consensus can be boiled down to the following:

- Climate change is currently happening.

- Humans are a significant causal factor.

1 The author would like to thank Jo Campbell, Jonathan Boston and Mike Gavin for useful comments on an earlier version of this article.
- Climate change poses a substantial threat to the economy and society.

- We will need to invest in strategies to cope with climate change (adaptation).

- We can lower the scale of impacts by reducing greenhouse gas emissions (mitigation).

Policy makers need to have confidence in the information guiding their decisions. The source of confidence for this consensus is to be found in the peerreviewed climate science literature. This literature is so vast that in 1988 the United Nations established a scientific review and advisory body on this topic: the Intergovernmental Panel on Climate Change (IPCC). Every six years the IPCC publishes an interdisciplinary scientific review and assessment that summarises the latest climate change research in three broad categories:

1. scientific basis;

2. impacts, adaptation and vulnerability; and

3. mitigation.

The latest is the Third Assessment Report (2001) - a 3,061page synthesis by over 1,000 authors and expert reviewers of over 11,000 peer-reviewed scientific studies. Over 10,000 scientific studies have been published in the peer-reviewed literature since then, which adds to the material for the Fourth Assessment Report due out in 2007. The result of this review process is a captivating story that is exceedingly relevant to policy makers the world over.

\section{Sea level rise}

Sea levels are rising globally. They rose by between 10 $\mathrm{cm}$ and $20 \mathrm{~cm}$ over the last 100 years, are currently rising at $1.8 \mathrm{~mm} / \mathrm{yr}$ (ten times faster than the rate observed for the last 3,000 years), and are forecast to rise by between $20 \mathrm{~cm}$ and $80 \mathrm{~cm}$ by the end of the century (IPCC, 2001a). This is due to thermal 
expansion of the oceans as they warm (a consequence of global atmospheric warming), and also because large volumes of ice that have been on the land for many thousands of years are melting and transferring some of this volume to the sea.

During ice ages sea levels drop because a large proportion of global precipitation falls as snow and stays on the land rather than running into the sea. This snow accumulates over many thousands of years, forming glaciers and ice sheets. Global sea levels during the last glacial maximum (around 20,000 years ago) were about 125 metres below current sea levels. As the climate warms during interglacials (such as the one we are experiencing now), this ice melts (flowing into the sea as water) and the proportion of precipitation that falls as snow declines. This raises sea levels. If the warming levels off, sea level rise will slow or cease, as has been the case for the last few thousand years. But with current global warming we can expect additional sea level rise as indicated above.

The source of water contributing to current sea level rise includes the huge ice sheets of Greenland and Antarctica. If the Greenland Ice Sheet melted completely it would add about 6 vertical metres to global sea levels. In Antarctica there are two ice sheets - the West Antarctic Ice Sheet (representing about 6 metres of global sea level), and the huge East Antarctic Ice Sheet (about 60 metres of global sea level). It would take thousands of years for these ice sheets to melt completely, even if global mean temperatures became warm enough to render them unsustainable - in the same way that it takes a while for a block of ice to melt once we have taken it out of the freezer. But as the melting progresses, more and more water runs off, adding to the volume of the oceans. There is also a risk that large chunks of ice sheets can break up and slide quickly into the oceans, which is a regular feature of ice sheets when they become unstable in a warming climate. This could raise sea levels suddenly long before the ice melts, in the same way that the level of a liquid in a glass rises when we put ice in a drink.

The British Antarctic Survey now indicates that this is a possibility for the West Antarctic Ice Sheet (Tirpak et al., 2005). Currently, $75 \%$ of the glaciers on the Antarctic peninsula (adjacent to the West Antarctic Ice Sheet) are in retreat (Rapley, 2005), and in 2002 the huge Larsen B Ice Shelf ${ }^{2}\left(3,250 \mathrm{~km}^{2}\right.$ in area and $220 \mathrm{~m}$ thick) disintegrated. This is consequentially leading to a two- to six-fold increase in the speed of glaciers at their terminus, which are now moving more quickly into the sea in the absence of this ice shelf barrier (NSIDC, 2002). In 1995 the 1,600 km² Larsen A ice shelf collapsed, followed in 1998 by the collapse of the $1,100 \mathrm{~km}^{2}$ Wilkins Ice Shelf. In the last 50 years some $13,000 \mathrm{~km}^{2}$ of ice shelf have collapsed in this region (Rapley, 2005). Current data also show that the Greenland Ice Sheet is melting faster than expected: the area of surface melt by the end of the 2002 season had broken all known records (NASA Earth Observatory, 2003). It is currently estimated that a global mean temperature increase of $2.7^{\circ} \mathrm{C}$ would surpass a threshold triggering the melting of the Greenland Ice Sheet (Tirpak et al., 2005). Sea ice in the Arctic is also in rapid decline. In September 2004, at the end of the summer melt, the extent of the sea ice was $13.4 \%$ less than average. Similar declines were observed in September 2003 (12\% less than average) and in September 2002 (15\% less than average) (NASA Earth Observatory, 2004). Some models predict a complete disappearance of Arctic summer sea ice by 2070 (NSIDC, 2004). In addition, the majority of the world's glaciers are in retreat, according to the World Glacier Monitoring Service.

\section{Global warming}

Global mean surface temperature has risen by $0.7^{\circ} \mathrm{C}$ since 1900 , and is projected by the IPCC to rise by between $1.4^{\circ} \mathrm{C}$ and $5.8^{\circ} \mathrm{C}$ above 1990 levels by 2100 (IPCC, 2001a). It is important to remember that we are talking about mean temperature for the global climate system (i.e. the mean of all temperature gauges all over the world) and not merely regional or seasonal variation in the weather. Furthermore, warming is unevenly distributed around the world - an average warming of $2^{\circ} \mathrm{C}$ globally may translate into $10^{\circ} \mathrm{C}$ of warming at the poles. To get an idea of the scale we are looking at: the last time the earth's mean surface temperature was $3-4^{\circ} \mathrm{C}$ warmer than today was around 34 million years ago, when Antarctica was $15^{\circ} \mathrm{C}$ warmer and was covered in forest (Barrett, 2001).

Current warming is attributed to a combination of

2 An 'ice shelf' is connected to land but floats on the sea (e.g. the Ross Ice Shelf over the Ross Sea in Antarctica). An 'ice sheet' is located entirely on the land; the only ones currently in existence are the Greenland Ice Sheet, the East Antarctic Ice Sheet and the West Antarctic Ice Sheet. The Greenland Ice Sheet is about $3 \mathrm{~km}$ deep at its summit. 
natural and human-induced influences, the latter arising predominantly from an increase in atmospheric $\mathrm{CO}_{2}$ concentrations.

\section{Greenhouse gas concentrations}

The atmosphere is made up of two major gases (nitrogen, 78\%, and oxygen, 21\%), with the remaining $1 \%$ made up of a large number of trace gases. A small number of these trace gases are known as 'greenhouse gases' due to their ability to re-emit infrared radiation reflecting from the earth's surface, acting as a form of insulation. This is due to the way their molecular structure interacts with infrared radiation. The natural greenhouse gases include carbon dioxide $\left(\mathrm{CO}_{2}\right)$, methane $\left(\mathrm{CH}_{4}\right)$, nitrogen oxide $\left(\mathrm{NO}_{2}\right)$ and water vapour $\left(\mathrm{H}_{2} \mathrm{O}\right)$. These greenhouse gases contribute to the natural greenhouse effect that keeps the earth's climate considerably warmer than it would be otherwise. If the earth had no greenhouse gases the global mean surface temperature would be about $-19^{\circ} \mathrm{C}$. With natural greenhouse gases we get a global mean surface temperature of about $14^{\circ} \mathrm{C}$ (a $33^{\circ} \mathrm{C}$ difference), which is much more suitable for life. If greenhouse gas concentrations increase, the mean surface temperature increases accordingly (IPCC, 2001a; Kump et al., 2004).
Atmospheric $\mathrm{CO}_{2}$ concentrations have increased from $280 \mathrm{ppm}$ (parts per million) in 1750 (IPCC, 2001a) to $374.9 \mathrm{ppm}$ in 2003 (Blasing and Jones, 2005). This is an increase of over $30 \%$. These levels are rising because of two global processes associated with economic development since the industrial revolution:

1. the transformation of large volumes of fossil carbon (e.g. coal, oil, natural gas) into atmospheric $\mathrm{CO}_{2}$ from burning these fuels; and

2. the transformation of large volumes of living carbon (e.g. wood, soil carbon) into atmospheric $\mathrm{CO}_{2}$ as a consequence of widespread deforestation.

About half of these $\mathrm{CO}_{2}$ emissions are reabsorbed by the biosphere (predominantly the oceans), leaving about half of all that is emitted behind in the atmosphere (IPCC, 2001a). As the volume of $\mathrm{CO}_{2}$ emissions has increased, atmospheric $\mathrm{CO}_{2}$ concentrations have increased. One of the best examples of this global trend is the 'Keeling Curve', which shows a steady increase in atmospheric $\mathrm{CO}_{2}$ concentrations from 1958 to the present (see Figure 1).

As indicated above, global warming is one of the consequences of rising $\mathrm{CO}_{2}$ levels. Another consequence is an increase in the acidity of the oceans. More atmospheric $\mathrm{CO}_{2}$ means more absorption of $\mathrm{CO}_{2}$ by the

Figure 1. The 'Keeling Curve' of atmospheric $\mathrm{CO}_{2}$

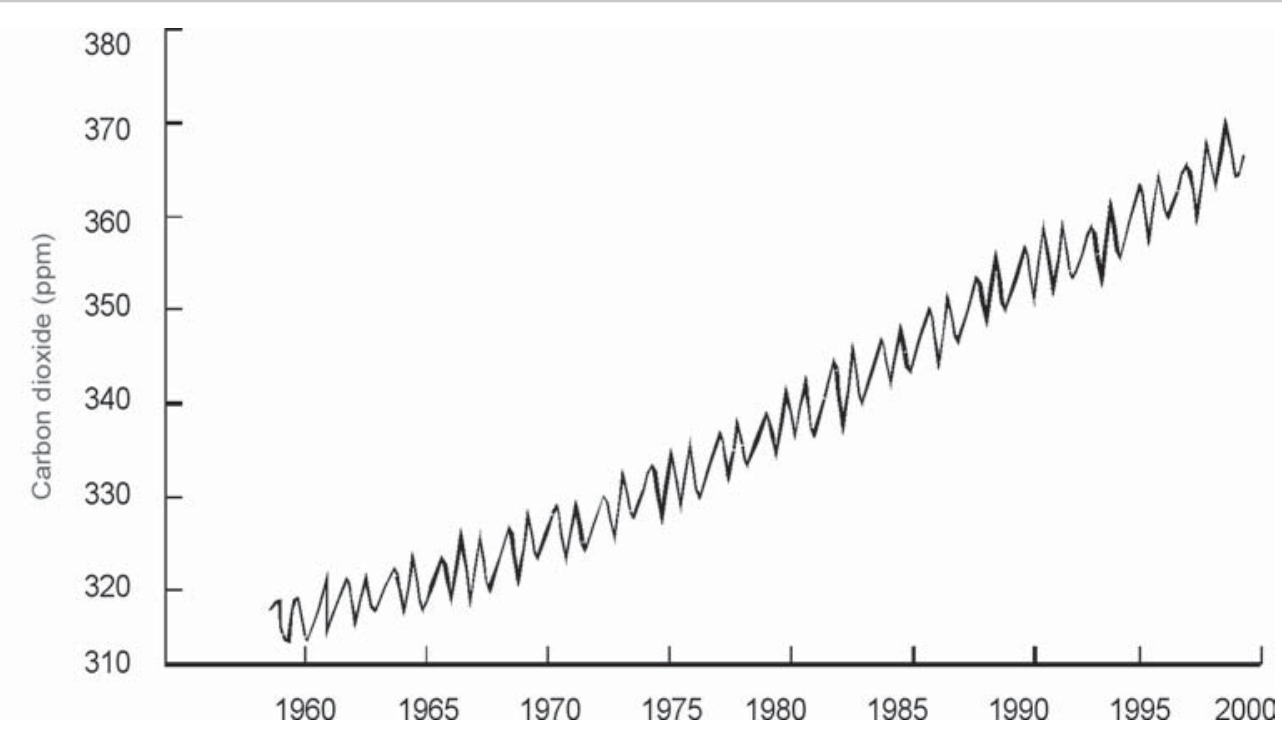

Figure 1: The rise of atmospheric $\mathrm{CO}_{2}$ concentrations as measured by Charles Keeling and collaborators at Mauna Loa, Hawaii. The unit 'ppm'stands for 'parts per million by volume. The zig-zag in the curve refers to seasonal variation. Source: Keeling and Whorf (2000). 


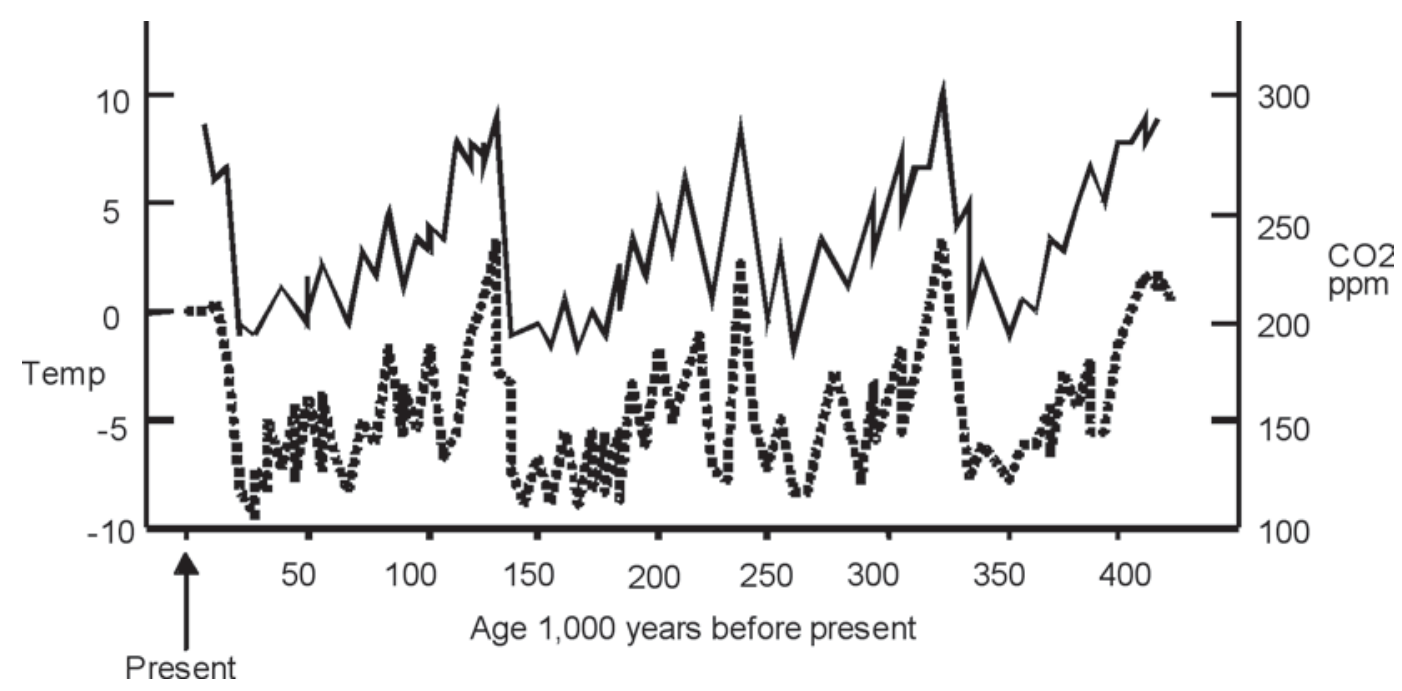

Figure 2: Vostok Ice Core record of variations in air temperature (relative to the current average temperature of $-55.5^{\circ} \mathrm{C}$ at Vostok) and $\mathrm{CO}_{2}$ concentrations from gas bubbles in the ice. Solid line $=\mathrm{CO}_{2}$ concentrations; dotted line $=$ temperature. Temperature measured in ${ }^{\circ} \mathrm{C}$. High points on the graph represent interglacial periods (like the one we are in currently), and lower points represent glaciations (the last glacial maximum being around 20,000 years ago). Data from Petit et al. (1999).

ocean, which leads to an increase in the amount of carbonic acid in the water. At the current rate of $\mathrm{CO}_{2}$ emissions, ocean surface water $\mathrm{pH}$ will be 0.4 units more acidic by 2100 - a level unprecedented for 20 million years (Turley et al., 2005). This has two adverse effects of concern to human society:

1. The rate at which the oceans are able to absorb $\mathrm{CO}_{2}$ declines.

2. The biochemistry of surface waters changes, causing:

a. coral bleaching (in combination with higher sea surface temperatures); and

b. disruption to marine food chains (particularly as plankton, shellfish and the eggs and sperm of fish have a low tolerance to changes in acidity). This can pose a significant threat to fish stocks and the fishing industry.

\section{Understanding the present by looking into the past}

To understand the significance of this increase in $\mathrm{CO}_{2}$ concentrations, it is helpful to look at the record we have built up of past climate through analysing several different records of past climate:
- the instrumental record (since the late 17th century);

- historical records of past living conditions (a few thousand years);

- tree ring data from living and archaeological wood specimens (a few thousand years);

- sediments on land and in lakes (thousands and tens of thousands of years);

- ice cores (hundreds of thousands of years); and

- deep ocean sediments (millions of years).

Of particular importance is ice core research from large ice sheets in Antarctica and Greenland, which provide a record of both past temperature and past atmospheric composition. Ice is laid down in annual layers, a little like tree rings. Air bubbles trapped in ice layers (as snow is compacted) provide a sample of past atmospheric composition and enable us to reconstruct a record of past changes in concentrations of different gases. Stable isotopes ${ }^{3}$ of oxygen in the ice can be measured in these

3 An isotope is one of several forms of an element (e.g. oxygen) with the same number of protons as the normal form but a different number of neutrons, giving it a different atomic weight. Unstable isotopes are radioactive, whereas stable isotopes are not. 
layers to give a proxy record of past temperature. The proportion of different isotopes in the ice is influenced by the temperature when this ice fell as snow. We can test the accuracy of this paleo-thermometer by measuring the oxygen isotopes in water, snow and ice in different parts of the world today (i.e. where there are different climates), and this has shown that the proxy record from isotopes matches the instrumental record very well (Alley, 2000).

When ice core data was used to reconstruct both past climates and past atmospheric gas compositions, an interesting correlation was discovered: when atmospheric
$\mathrm{CO}_{2}$ concentrations were high, mean temperatures were also high. When atmospheric $\mathrm{CO}_{2}$ concentrations were low, mean temperatures were low. A remarkable record of this parallel process can be seen in ice core records in both Greenland and Antarctica. The most famous is the Vostok Ice Core from Antarctica (Figure 2).

This close association between atmospheric $\mathrm{CO}_{2}$ concentrations and mean surface temperature helps to show the likely effect of an increase in $\mathrm{CO}_{2}$ concentrations as a consequence of industrial emissions. Broadly speaking, an increase in $\mathrm{CO}_{2}$

Figure 3. Current and future projections of atmospheric $\mathrm{CO}_{2}$ concentration

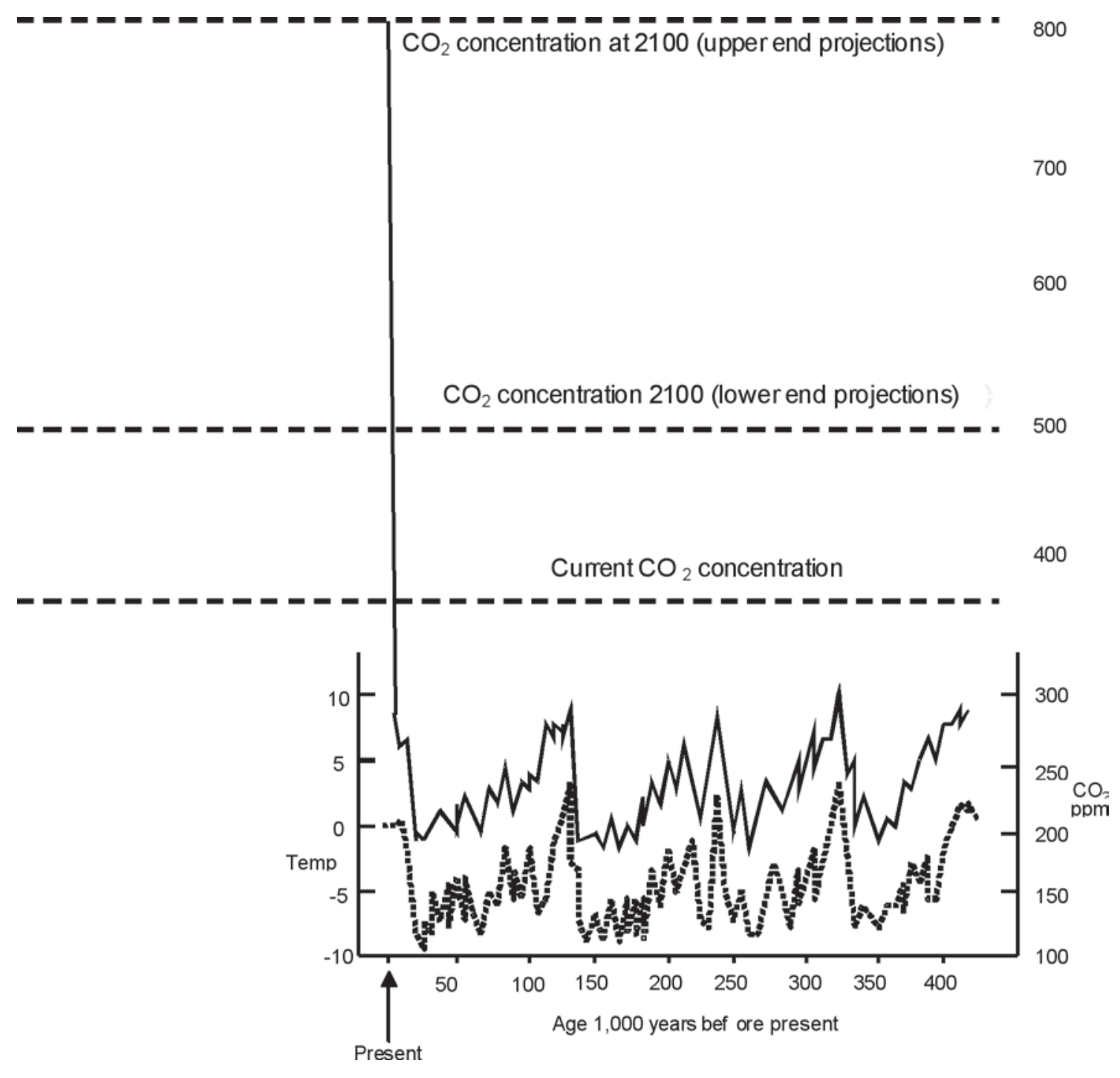

Figure 3: Current and future projections of atmospheric $\mathrm{CO}_{2}$ concentrations based on the Vostok Ice Core baseline. Current $\mathrm{CO}_{2}$ concentrations are well above interglacial peak concentrations for the last three interglacials. Future projections based on IPCC (2001a) projections under different mitigation scenarios. 
concentration is likely to lead to an increase in mean surface temperature because of the way $\mathrm{CO}_{2}$ functions as a greenhouse gas, together with feedbacks in the climate system responding to increased temperature. One of the key feedbacks associated with warming derived from increases in atmospheric $\mathrm{CO}_{2}$ is additional evaporation leading to an increase in atmospheric water vapour (a much more potent greenhouse gas than $\mathrm{CO}_{2}$ ). Consequently, the total warming triggered by additional $\mathrm{CO}_{2}$ is greater than the warming that can be attributed to increases in $\mathrm{CO}_{2}$ alone. There are many other feedbacks in the climate system, some positive (reinforcing the warming trend, e.g. drought, forest fires, snow/ice melt exposing darker land surfaces) and others negative (counterbalancing, e.g. increased reflection of solar radiation from increased cloud cover). It is the net effect of all positive and negative feedbacks that leads to an overall increase or decrease in mean global temperature. It is on this basis that the IPCC concluded that current trends in $\mathrm{CO}_{2}$ emissions will translate into mean global surface temperature increases in coming decades.

One way to get a sense of the scale of change we may be facing (especially for a scenario where we do not cut back on $\mathrm{CO}_{2}$ emissions) is to look at future projections for atmospheric $\mathrm{CO}_{2}$ concentrations on the basis of current emission trends. Figure 3 shows what current atmospheric $\mathrm{CO}_{2}$ concentrations look like against the historical backdrop, and what is likely for the next 100 years at two projection ranges (one very conservative and therefore accompanied by a high level of confidence, the other still within the realms of possibility but accompanied by more uncertainty).

As can be seen from this graph, current $\mathrm{CO}_{2}$ concentrations are higher than they have been over the last 420,000 years (Petit et al., 1999; IPCC, 2001a). More recent research by the European Project for Ice Coring in Antarctica pushes this date back to 650,000 years (Siegenthaler et al., 2005). According to this study, current $\mathrm{CO}_{2}$ concentrations are $30 \%$ higher; $\mathrm{CH}_{4}$ (methane - a much more potent greenhouse gas) is $130 \%$ higher; and the rate of $\mathrm{CO}_{2}$ increase is 200 times faster than at any time in the last 650,000 years. The IPCC also points out that current atmospheric $\mathrm{CO}_{2}$ concentrations are quite possibly higher than at any time in the last 20 million years (IPCC, 2001a).
At the current rate of increase there is a high probability that atmospheric $\mathrm{CO}_{2}$ concentrations will rise to double the pre-industrial level (from $280 \mathrm{ppm}$ to 560 $\mathrm{ppm}$ ) some time this century. The growing consensus among climate scientists is that this would lead to a mean warming of $3^{\circ} \mathrm{C}$ (Kerr, 2004). Recall that $2.7^{\circ} \mathrm{C}$ is probably enough to melt the Greenland Ice Sheet (other potential consequences are discussed below).

Another interesting finding from ice core climate research relates to changes in climate variability (the range of variation in the climate). During the last several hundred thousand years the climate has been characterised by huge and rapid shifts. Higher resolution paleoclimate records (especially for the last 100,000 years) show that huge swings in the climate have been the norm for this stage in the earth's history, and archaeological evidence suggests how very challenging this was for early human societies trying to cope with (and survive) the ice age. So, anyone who says 'climate change has happened throughout our prehistory' is right. If they also say 'and therefore it is not going to be a problem for contemporary society', they are way off the mark.

\section{Climate variability}

To understand why future climate change is so threatening it is important to look more closely at the last 10,000 years in relation to the very unstable period that preceded it. The last 10,000 years is known as the Holocene Epoch, which refers to the current, relatively stable, warm period (interglacial) that we dwell in. Figure 4 shows a higher-resolution representation of past climate using oxygen isotopes as a proxy for temperature for the last 80,000 years.

This graph shows how the hugely variable climate that has characterised the last half million years changed to a very stable phase around 10,000 years ago. Agricultural societies first developed at this time (i.e. 12,000-10,000 years ago). Prior to this stable period, climate variability was much greater and would have posed a serious problem for potential agriculturalists who, as intelligent humans some 15,000 years ago (we have not evolved much as a species since that time), had to stick to nomadic hunting and gathering (see Burroughs, 2005). One distinct possibility is that the agricultural revolution happened at the same time that a change in the climate allowed it to become possible. 
Figure 4. Transition from the last ice-age to the current stable warm period

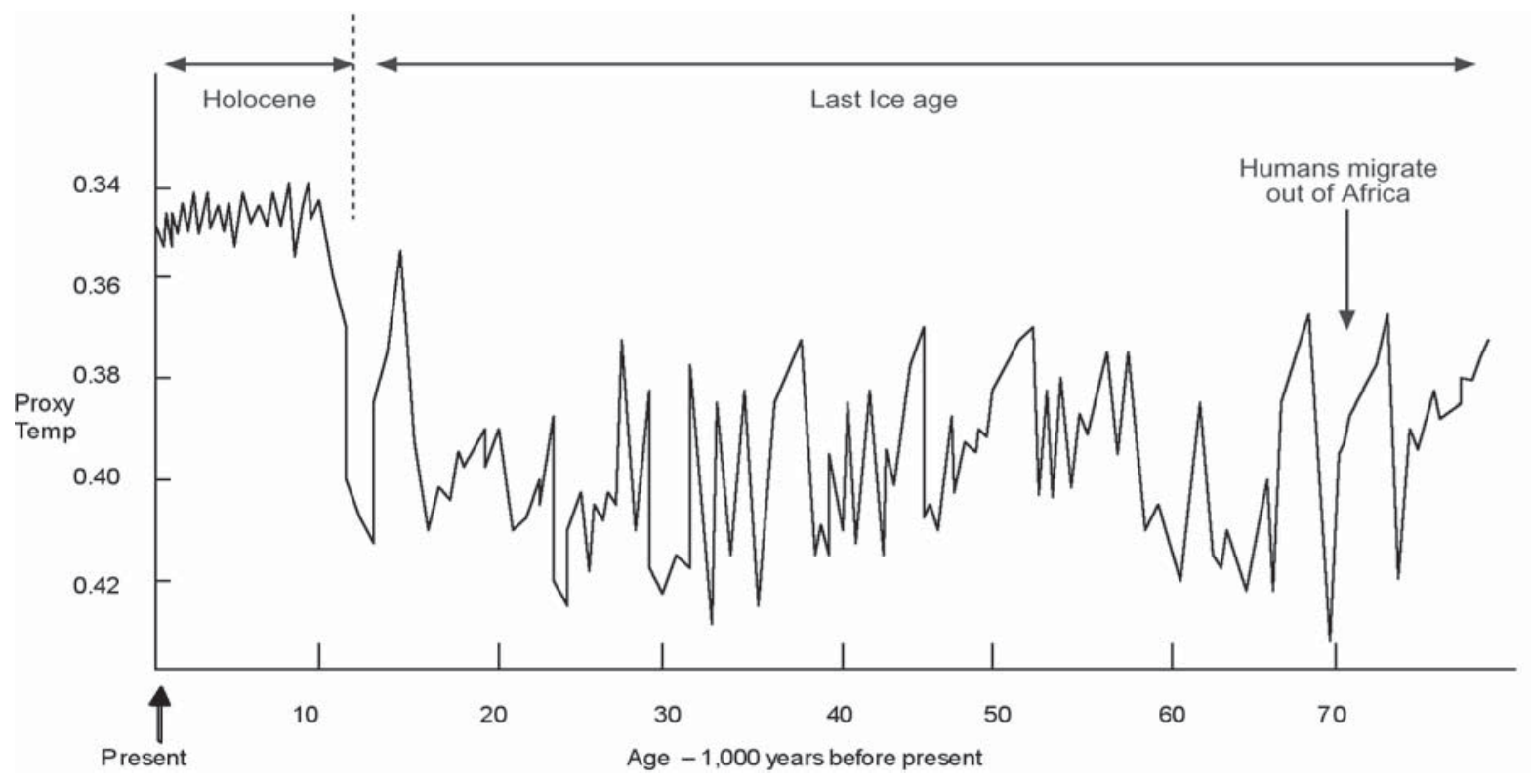

Figure 4: Transition from the chaotic climate of the last ice age to the much more stable warm period of the Holocene (10,000 ago - present). Past temperature is measured as concentrations of oxygen 18 isotopes from the GISP2 ice core (oloo) (Greenland). Oxygen 18 isotopes are displayed on the vertical (Y) axis, but the key theme in this graph is the substantial difference in climate variability signalled prior to 10,000 years ago. Source: data from Greenland Ice Sheet Project 2 (GISP2).

Another feature of past climate that this graph (and many like it) reveals is the way that the climate has changed very significantly and very abruptly in the past. A good example is the sudden drop in temperature just before the Holocene (below and slightly to the right of the dotted line in Figure 4). This sudden cooling happened 13,000 years ago as we were climbing out of the last ice age, and is known to geographers and geologists as the 'Younger Dryas'. Temperatures abruptly dropped to levels similar to the coldest part of the ice age, stayed cold for 1,300 years, and then abruptly warmed again (by $7^{\circ} \mathrm{C}$ ), in three steps each lasting five years and spread over a 40-50-year period. This shows that sudden temperature shifts of $1.4^{\circ} \mathrm{C}-5.8^{\circ} \mathrm{C}$ in mean global temperature (i.e. the range predicted for this century by the IPCC) are certainly possible.

\section{Tipping point}

One of the threats that accompanies contemporary climate change is that global warming in the coming decades could push our stable climate beyond a critical tipping point, where it shifts into a different system state. One possibility is a return to the colder and highly variable climate that has been normal for hundreds of thousands of years (e.g. the righthand side of Figure 4). But because current and projected atmospheric $\mathrm{CO}_{2}$ concentrations are already out of proportion to conditions that prevailed for the last 650,000 years, there is a possibility that a shift to a new system state will take us into very uncharted territory, or at least into conditions that have not been seen for many millions of years (see Barrett in this volume).

There are a number of key components of the global climate system that, if triggered, could lead to runaway climate change, with potentially catastrophic consequences. These include:

- Shutdown of the northern portion of the Gulf Stream, leading to sudden regional cooling in western and northern Europe. This can be caused by the dilution 
of North Atlantic surface waters as a consequence of melting ice caps and sea ice (Clark et al., 2002).

- Sudden sea level rise: portions of large ice sheets fragmenting and sliding into the sea, transferring their volume to the oceans and raising sea levels abruptly by tens of centimetres or a few metres;

- Tropical drought: a shift to a drier seasonal climate in the Amazon Basin and South East Asia, leading to the loss of their tropical rain forests and the release of large volumes of $\mathrm{CO}_{2}$ from forest fires. Droughts have been intensifying in South East Asia and Amazonia in recent years and have been accompanied by large-scale forest fires. If the dry season in the Amazon Basin extends from four to six months, there is an increased chance of losing the rainforest (see Cox et al., 2004).

- Destabilisation of global methane reservoirs: release of huge volumes of methane (more than 20 times more potent than $\mathrm{CO}_{2}$ as a greenhouse gas) from the sea bed and thawing permafrost. The record of permafrost thaw in recent years is well established (see NASA Earth Observatory website). The oceanic methane reservoir (thousands of gigatons of carbon much bigger than the conventional fossil fuel reservoir) exists as a form of ice in seabed sediments (below 500 metres depth in warmer regions and below 200 metres in the Arctic), and remains stable under cold water temperatures and/or high pressure (Kennett, 2002). The releases of large volumes of methane from this source have been associated with large submarine 'landslides' occurring in tropical waters during cold periods and in polar waters during warm periods (Maslin et al., 2004), possibly due to changes in ocean currents at intermediate depths. If this methane were released it would trigger further global warming.

\section{Challenging civilisations}

Clearly, human communities lived in many parts of the world during the chaotic climate prior to the Holocene, which suggests that we will survive if conditions return to this situation. Surviving as a species and thriving as a global civilisation are two different things. One key difference between the ice age and now is that back then our total population would have numbered in the millions, whereas now we have 6.5 billion people to support (rising by 90 million every year), and most of us are reliant on a relatively stable climate for our food supply and a relatively stable economic system to distribute it (almost half of the human population now live in cities).

It is also important to remember that civilisations only became possible when agriculture enabled the production of food surpluses, allowing a sedentary existence in towns and cities, population increases, a division of labour and the build-up of large armies. Even though climate variability during the Holocene has been relatively small (compared to the norm for the last 400,000 years), these relatively small shifts have been enough to collapse civilisations. For example, around 5,000 years ago there was a relatively minor climate shift that transformed the Sahara from arable land to desert.

Historically, one of the biggest killers of human societies is drought. Droughts lead to crop failures and food shortages, which bring economic losses that can help civilisations fail. The demise of the Akkadian civilisation of Mesopotamia 4,200 years ago, the fragmentation of Egyptian civilisation following the Seventh and Eight Dynasties around the same time, the sudden decline of the eastern Mediterranean economy around 3,000 years ago and the fall of the Mayan civilisation in the ninth century all coincided with shifts to a drier climate (Burroughs, 2005). None of these shifts was accompanied by the scale of atmospheric $\mathrm{CO}_{2}$ concentrations we now face. Of course, we now have more developed economies and technologies, but our economies still rely heavily on natural resources that, in turn, are reliant on a favourable climate.

\section{Agriculture}

Agriculture is based on the geographical intersection of fertile soils with a favourable climate and water supply. When the climate regime changes, this important partnership is threatened. This theme did not escape the Pentagon, which commissioned a report in 2003 on the threat of abrupt climate change in the $21 \mathrm{st}$ century. It anticipates 'harsher winter weather conditions, sharply reduced soil moisture, and more intense winds in certain regions that currently provide a significant fraction of the world's food production. With inadequate preparation, the result could be a significant drop in the human carrying capacity of the Earth's environment.' It warns of food shortages due to 
decreases in net global agricultural production, decreased availability of fresh water in key regions, and disrupted access to energy supplies for the United States (Schwartz and Randall, 2003).

Even in the absence of a change in the system state of the global climate (e.g. shifting from a stable to a very unstable condition), warming trends within the current system state are likely to lead to shifts in the distribution of precipitation, with droughts intensifying in some areas and increased rainfall (and consequent flooding) in others. Conservative estimates show that water shortages are likely to affect agricultural productivity, particularly in drier regions such as south western and south eastern Australia, south western United States, Mexico, much of northern Africa, parts of northern China, parts of India, Central Asia, the Middle East (IPCC, 2001b; Arnell, 2004) and eastern New Zealand (IPCC, 2001b).

\section{Storms}

Increased sea surface temperatures lead to increased evaporation, which puts more water vapour into the atmosphere. This increases the amount of latent heat in the weather system, which means there is more energy for storms (i.e. they get more powerful). Different studies published in the top scientific journals (Science and Nature) during 2005 independently reported an increase (globally) in the frequency and/or severity of hurricanes. One study using satellite data found that the number of category 4 and 5 storms doubled during the past 35 years in an environment of increasing sea surface temperature. They concluded that larger storms now occur 20-35\% more frequently than smaller storms (Webster et al., 2005). Another study looked into storm intensity and found that the power of storms had increased significantly over the past 30 years in all the regions studied, a result that is consistent with an increase in sea surface temperature (Emanuel, 2005). Because no storm comes with a bar code to identify whether it is a consequence of climate change, we can never blame climate change as the sole culprit for any single event. What we can do is expect an increase in the frequency of severe storms and the cost they impose on the economy if the global climate continues to warm.

Storms over the ocean generate storm surges which temporarily raise sea levels locally (as happened in New
Orleans in 2005). When combined with the global rise in sea levels expected in the $21 \mathrm{st}$ century $(20-80 \mathrm{~cm})$, storm surges from a larger number of more powerful storms pose a significant threat of economic damage to low-lying regions and countries, coastal property, infrastructures and coastal cities. The cost of these kinds of events is not insignificant. When insurance costs are combined with Federal outlays, the total cost of Hurricane Katrina has been estimated at US\$200 billion (MSNBC, 2005).

\section{Adaptation and mitigation}

There is not room here to present the many other impacts of climate change, in areas ranging from human health to biodiversity, fisheries sustainability, coastal erosion, financial systems, insurance, infrastructures and migration, to name a few. Those inspired to have a closer look can explore these themes by reading the 'Summary for Policy Makers' for each of the three volumes of the IPCC Third Assessment Report (available online at http://www.ipcc.ch/).

Ultimately, climate change will be expensive, whether from the direct impacts of a changing climate on our economies, the cost of insurance, or from the investments we will need to make in adaptation and mitigation. Either way, it will continue to climb up the policy agenda in coming years, as more and more people realise the scale of the issues and the nature of the threats.

Two things remain clear:

1. Adaptation: we are committed to future climate change irrespective of what we do regarding emissions reductions, and as such we will need to invest in adapting to this change.

2. Mitigation: if we want to be capable of adapting successfully we will need to lower the scale of the impacts that climate change promises to deliver. Fortunately, we do have some degree of control over this, and it relates primarily to the volume of greenhouse gas emissions we choose to put into the atmosphere annually. This is a global challenge and the target is to stabilise greenhouse gas concentrations to avoid dangerous anthropogenic interference with the climate system (to use the language of Article 2 of the United Nations Framework Convention on Climate Change).

There is also insufficient room here to adequately explore the themes of adaptation and mitigation, but a few 
things are worth mentioning. Because about $80 \%$ of human-induced greenhouse gas emissions have arisen from the burning of fossil fuels, any realistic approach to mitigation will need to confront the global carbonbased energy system and change it (sequester the carbon, move to alternatives, dramatically increase energy efficiency, and lower per capita demand). This will not be easy, as currently $85 \%$ of global energy consumption is based on fossil fuels, with $86 \%$ projected for 2025 (EIA, 2004). In the absence of any significant change in energy systems, continued growth in world fossil fuel use will increase global $\mathrm{CO}_{2}$ emissions by $1.9 \%$ per year for the first quarter of the current century. This would mean an increase from 23,899 million metric tons in 2001 to 37,124 million metric tons in 2025 (EIA, 2004). On this basis, by 2025 global $\mathrm{CO}_{2}$ emissions will be $72 \%$ higher than 1990 levels. In the meantime, the Kyoto Protocol is attempting to get countries to stabilise emissions at 1990 levels.

No country can claim to be exempt from the impacts of climate change or its causes in carbon-based energy use and deforestation since the industrial revolution. For this reason the response has to be a global partnership, with each nation making a contribution to the solution. This also means that domestic policy and international negotiations need to be in sync. No single country can solve this problem alone. If the United States and the United Kingdom adhered to an emissions target but China and India didn't pursue one we would still be no better off as a global community.

Even countries like Tuvalu and New Zealand that stand to suffer the impacts but do not make a major contribution to the global problem (because of low population rather than low per capita emissions) will need to participate in this solution partnership. Domestic policy in such countries amounts to a contribution in physical terms to the global emissions reduction goal, but also enables those countries to advocate strongly in the intergovernmental arena and avoid the less convincing 'do as I say, not as I do' approach to international negotiations.

\section{Conclusion}

Climate change presents a significant challenge, but one that we are definitely capable of meeting as a global community. Understanding the nature of the risks involved can help in priority setting for present and future actions. Furthermore, the scale of the response needs to be in proportion with these risks.

The solution path invites both change and continuity: change in the way we fuel our economies and manage our resources; continuity in the role of innovation and ingenuity in the task of progress. We have an abundance of intellectual resources for this task. All that is needed are the policy and political resources to make it happen. A significant barrier is the perceived cost of choosing this path. Understanding the scientific backdrop to climate change policy, however, can help cultivate an appreciation that working to protect what we have spent the last few centuries building is a very worthy investment.

\section{References}

Alley, R.B. (2000) The Two Mile High Time Machine: ice cores, abrupt climate change, and our future, New Jersey: Princeton University Press

Arnell, N. (2004) 'Climate change and water resources: SRES emissions and socio-economic scenarios', Global Environmental Change, 14, pp.31-52

Barrett, P (2001) 'Climate change - an Antarctic perspective,' New Zealand Science Review, 58(1), pp. 18-23

(2006) 'Will unchecked global warming destroy civilisation by century's end? What $3{ }^{\circ} \mathrm{C}$ of global warming really means', Policy Quarterly, 2(1)

Blashing, T.J. and S. Jones (2005) 'Current greenhouse concentrations', Carbon Dioxide Information Analysis Centre (CDIAC), http://cdiac.esd.ornl.gov/pns/ current_ghg.html

Burroughs, W.J. (2005) Climate Change in Prehistory: the end of the reign of chaos, Cambridge: Cambridge University Press

Clark, P.U., N.G. Pisias, T.F. Stocker and J. Weaver (2002) 'The role of the thermohaline circulation in abrupt climate change,' Nature, 415, pp.863-9

Cox, P.M. et al. (2004) 'Amazonian forest dieback under climate-carbon cycle projections for the 21st century', Theoretical and Applied Climatology, 78, pp.137-56

EIA (2005) 'International energy outlook 2004: world energy and economic outlook', http://www.eia.doe.gov/ oiaf/ieo/world.html 
Emanuel, K. (2005) 'Increasing destructiveness of tropical cyclones over the past 30 years', Nature, 436(7051), pp.686-8

IPCC (Intergovernmental Panel on Climate Change) (2001a) Climate Change 2001: the scientific basis. Third assessment report, Cambridge: Cambridge University Press

(2001b). Climate Change 2001: impacts, adaptation, and vulnerability. Third assessment report, Cambridge: Cambridge University Press

Keeling, C.D. and T.P. Whorf (2000) 'Atmospheric $\mathrm{CO}_{2}$ records from sites in the SIO air sampling network', in Trends: a compendium of data on global change, Oak Ridge, Tenn.: Carbon Dioxide Information Analysis Center, Oak Ridge National Laboratory, US Department of Energy

(2005) Atmospheric $\mathrm{CO}_{2}$ records from sites in the SIO air sampling network', in Trends: a compendium of data on global change, Oak Ridge, Tenn.: Carbon Dioxide Information Analysis Center, Oak Ridge National Laboratory, US Department of Energy, http:// cdiac.esd.ornl.gov/trends/co2/sio-mlo.htm

Kennett, J.P. (2002) Methane Hydrates in Quaternary Climate Change: the Clathrate gun hypothesis, Washington D.C.: American Geophysical Union

Kerr, R.A. (2004) 'News focus - three degrees of consensus', Science, 305, pp.932-4

Kump, L.R., J.F. Kasting and R.G. Crane (2004) The Earth System (second edition), New Jersey: Pearson Education

Maslin M., M. Owen, S. Day and D. Long (2004) 'Linking continental-slope failures and climate change: testing the Clathrate gun hypothesis', Geology, 32(1), pp.53-6

MSNBC (2005) 'How Hurricane Katrina's costs are adding up', http://www.msnbc.msc.com/id/9329293/

NASA Earth Observatory (2003) 'Vanishing ice', http:/ /earthobservatory.nasa.gov/Study/vanishing/

(2004) 'Arctic sea ice decline continues', http:// earthobservatory.nasa.gov/Newsroom/NewImages/ images.php3?img_id=16689/

NSIDC (National Snow and Ice Data Centre) (2002) 'Larsen B Ice Shelf collapses in Antarctica', http:// nsidc.org/iceshelves/larsenb2002/
__ (2004) 'Arctic sea ice decline continues', http:// nsdic.org/news/

Petit, J.R. et al. (1999) 'Climate and atmospheric history of the past 420,000 years from the Vostok Ice Core, Antarctica', Nature, 399, pp.429-36

Rapley, C. (2005) 'Antarctic ice sheet and sea level rise', paper presented to the International Symposium on Stabilisation of Greenhouse Gases, Exeter, February 2005, http://www.stabilisation2005.com/

Schwartz, P. and D. Randall (2003) 'An abrupt climate change scenario and its implications for United States national security', October, http://www.ems.org/ climate/pentagon_climate_change.html

Siegenthaler, U. et al. (2005) 'Stable carbon cycleclimate relationship during the late Pleistocene', Science, 310(5752), pp.1313-7

Starkman, D. (2005) 'The cost of insurance', Washington Post, 8 November

Tirpak, D et al. (2005) 'Report of the International Scientific Steering Committee, International Symposium on the Stabilisation of Greenhouse Gas Concentrations', Exeter, February 2005, http:// www.stabilisation2005.com/outcomes.html

Turley, C. et al. (2005) 'Reviewing the impact of increased atmospheric $\mathrm{CO}_{2}$ on oceanic $\mathrm{pH}$ and the marine ecosystem', paper presented to the International Symposium on Stabilisation of Greenhouse Gases, Exeter, February 2005, http:// www.stabilisation2005.com/

Webster, P.J., G.J. Holland, J.A. Curry and H.-R. Chang (2005) 'Changes in tropical cyclone number, duration, and intensity in a warming environment', Science, 309(5742), pp.1844-6

Dr Sean Weaver is a lecturer in

Environmental Studies and Geography at the School of Earth Sciences, Victoria University of Wellington. His research specialises in the intersection of climate change science and policy, with a particular emphasis on the conservation of natural forests in climate change mitigation. 